\title{
Bleeding Diathesis in Multiple Myeloma: A Rare Presentation of a Dreadful Emergency With Management Nightmare
}

\author{
Sabih Rahman ${ }^{1}$, Sindhusha Veeraballi ${ }^{2}$, Kok Hoe Chan ${ }^{1}$, Hamid S. Shaaban ${ }^{3}$ \\ 1. Internal Medicine, Saint Michael's Medical Center, Newark, USA 2. Medical Education, Saint Michael's Medical \\ Center, Newark, USA 3. Hematology and Oncology, Saint Michael's Medical Center, Newark, USA
}

Corresponding author: Kok Hoe Chan, kokhoedelcos.chan@gmail.com

\begin{abstract}
Multiple myeloma is a neoplastic disorder of plasma cells. An abnormal coagulation profile, though commonly seen in multiple myeloma, can rarely manifest as life-threatening hemorrhagic complications. Bleeding tendencies in multiple myeloma can be explained by a variety of mechanisms such as dysfibrinogenemia, paraprotein-induced platelet dysfunction, shortened platelet survival, damage to the vascular endothelium, and acquired von-Willebrand syndrome. Herein, we report a 61-year-old female who presented with the signs and symptoms of hemorrhagic shock with multiple myeloma, which remained refractory to a massive transfusion protocol. Her condition stabilized when she was started on dexamethasone and antifibrinolytic infusion targeting acquired dysfibrinogenemia. To the best of our knowledge, hemorrhagic shock secondary to dysfibrinogenemia is an unusual phenomenon in multiple myeloma.
\end{abstract}

Categories: Internal Medicine, Oncology, Hematology

Keywords: bleeding diathesis, multiple myeloma, acquired dysfibrinogenemia

\section{Introduction}

Multiple myeloma is plasma cell dyscrasias with the presence of excess monoclonal paraprotein resulting from the abnormal proliferation of monoclonal plasma cells in the bone marrow [1]. Multiple myeloma was first described in 1848, represents $1 \%$ of all malignancies worldwide, more than $10 \%$ of all hematological malignancies, and is the 14th most common cause of cancer deaths in the United States [2-3]. Various somatic and oncogenic mutations and chromosomal aberrations are associated with the mutation of plasma cells, which leads to the formation of a premalignant condition called monoclonal gammopathy of undetermined significance (MGUS) that then progresses to smoldering multiple myeloma. Further progression develops symptomatic and fatal multiple myeloma [2].

Review began 03/14/2021 Review ended 03/17/2021 Published 03/19/2021

\section{Copyright 2021}

Rahman et al. This is an open access article distributed under the terms of the Creative Commons Attribution License CC-BY 4.0., which permits unrestricted use, distribution, and reproduction in any medium, provided the original author and source are credited.
An abnormal coagulation profile, though commonly seen in multiple myeloma, can rarely manifest as lifethreatening hemorrhagic complications. Bleeding tendencies in multiple myeloma can be explained by a variety of mechanisms such as dysfibrinogenemia secondary to the inhibition of fibrin monomers by the FAB portion of paraprotein molecules, paraprotein-induced platelet dysfunction, shortened platelet survival, damage to vascular endothelium, and acquired von-Willebrand syndrome [4].

Herein, we report a 61-year-old female who presented with signs and symptoms of hemorrhagic shock. She remained refractory to a massive transfusion protocol with packed red blood cells, platelets, coagulation factor replacement, vitamin K, folic acid therapy, and desmopressin. Her condition stabilized when she was started on dexamethasone and antifibrinolytic infusion targeting acquired dysfibrinogenemia. Later, she was diagnosed with multiple myeloma and remarkably responded to the treatment of multiple myeloma. Hemorrhagic shock secondary to dysfibrinogenemia is an unusual phenomenon in multiple myeloma.

\section{Case Presentation}

A 61-year-old female with a past medical history of hypertension and coronary artery disease status postpercutaneous coronary intervention presented to the emergency room with generalized weakness and dizziness for a day. On initial encounter, her temperature was 99.8 degrees Fahrenheit, respiratory rate 18 breaths/min, heart rate $115 \mathrm{bpm}$, and blood pressure 77/33 $\mathrm{mmHg}$. Her initial laboratory data revealed hemoglobin of $5.5 \mathrm{~g} / \mathrm{dL}$ (13.5-17.5 g/dL), which dropped to $3.6 \mathrm{~g} / \mathrm{dL}$ in six hours, platelets of $142 \mathrm{k}(150 \mathrm{k}$ $450 \mathrm{k}$ ). Coagulation studies revealed fibrin degradation products $<5 \mathrm{mg} / \mathrm{dL}$ ( $<10 \mathrm{mg} / \mathrm{L})$, low haptoglobin 13.7 $\mathrm{mg} / \mathrm{dL}$ (50-220 mg/dL), low fibrinogen $156 \mathrm{mg} / \mathrm{dL}$ (200-400 mg/dL), prolonged prothrombin time 22.1s (11$12.5 \mathrm{~s})$, international normalized ratio (INR) $1.82(<1.1)$, and prolonged partial thromboplastin time $58.7 \mathrm{~s}$ (30-40s). Factor VIII activity was 184\% (57\%-163\%) and von Willebrand factor (vWF) activity was normal $150 \%$ (50\%-200\%). Direct Coombs test was negative, and reduced activity of coagulation factors of II, VII, and $X$ activity was found. Blood urea nitrogen was $56 \mathrm{mg} / \mathrm{dL}(6-24 \mathrm{mg} / \mathrm{dL})$ and creatinine was $3.5 \mathrm{mg} / \mathrm{dL}$ (0.5-1.0 mg/dL). The septic workup was negative. She was transferred to the medical intensive care unit 


\section{Cureus}

where she remained unstable even after immediate fluid resuscitation and massive transfusion protocol. She received vitamin K, vitamin B12, folic acid, desmopressin to address uremic platelet dysfunction,

antifibrinolytic (Amicar) infusion, and intravenous dexamethasone to address acquired dysfibrinogenemia after which her bleeding finally stopped. She was found to have an M-spike $(61.8 \%, 33.4 \mathrm{mg} / \mathrm{dL})$ on protein electrophoresis, hypercalcemia, and lytic lesions of her long bone shafts on the skeletal survey (Figure 1).

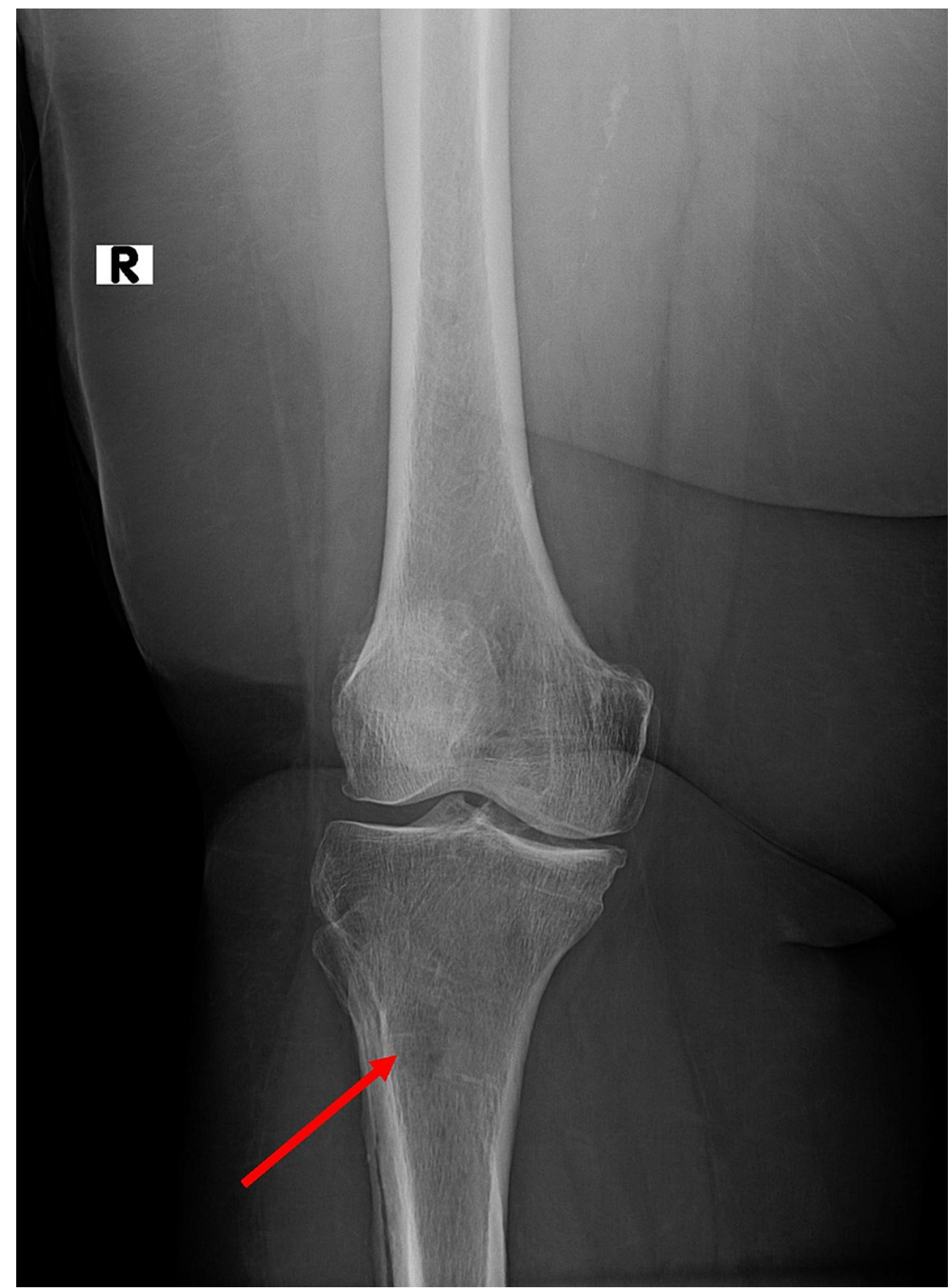

FIGURE 1: Skeletal survey showed lytic lesions of her long bone shafts

Her chest X-ray revealed a non-displaced fracture of her left clavicle (Figure 2). 


\section{Cureus}

LT

FIGURE 2: Chest X-ray revealed a non-displaced fracture of her left clavicle

A new CT scan showed subtle lytic lesions involving the anterior aspect of her second left rib. It also showed paravertebral soft tissue mass at the T6-T7 level with the destruction of part of the T6 vertebral body (Figure 3).

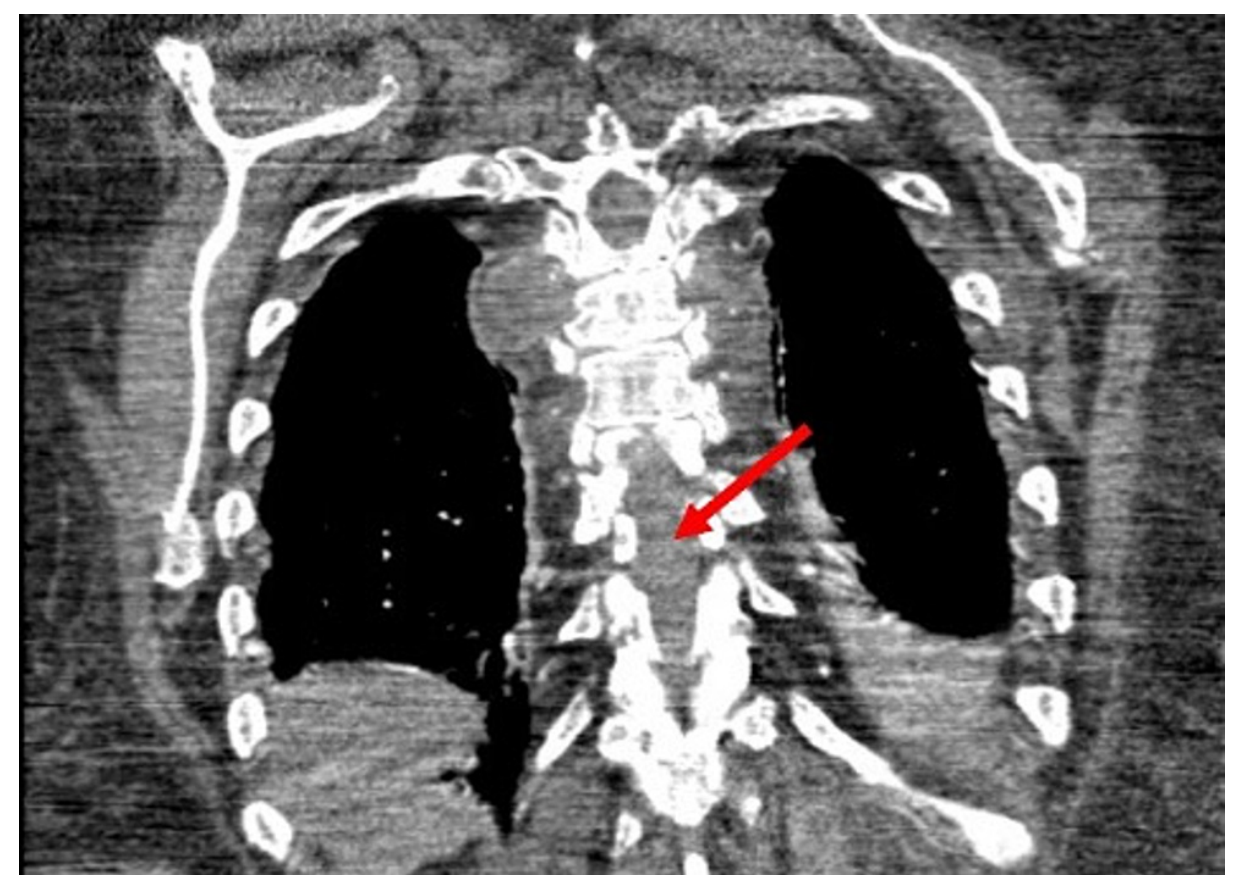

FIGURE 3: The CT scan showed a paravertebral soft tissue mass at the T6-T7 level with the destruction of part of the T6 vertebral body

Further immunohistochemical analysis of the bone marrow biopsy showed $60 \%-70 \%$ of $\mathrm{CD} 138$ positive and lambda light chains expressing monoclonal lambda/immunoglobulin G (IgG) plasma cells confirming the diagnosis of lambda/IgG multiple myeloma. The coagulopathy was controlled when she was started on chemotherapy for multiple myeloma. On follow-up, her fibrinogen was remarkedly improved to $244 \mathrm{mg} / \mathrm{dl}$ (200-400 mg/dl).

\section{Discussion}


Multiple myeloma commonly presents with a wide variety of symptoms, known as CRAB symptoms, with C hypercalcemia (13\%), R - renal failure (20\%-40\%), A - anemia (70\%), and B - lytic bone lesions (80\%), in addition to weight loss (24\%) and recurrent infections [4]. The National Comprehensive Cancer Network (NCCN) criteria for the diagnosis of active multiple myeloma includes clonal bone marrow plasma cells $\geqslant 10 \%$, the presence of biopsy-confirmed bony or extramedullary plasmacytoma, and one or more myelomadefining events such as hypercalcemia $(>1 \mathrm{mg} / \mathrm{dl}$ higher than the upper limit), renal failure (creatinine $>2$ $\mathrm{mg} / \mathrm{dL}$ or creatinine clearance $<40 \mathrm{~mL} / \mathrm{min}$ ), anemia (hemoglobin $<10 \mathrm{~g} / \mathrm{dL}$ or hemoglobin $>2 \mathrm{~g} / \mathrm{dL}$ below the lower limit of normal), one or more osteolytic bone lesions on skeletal radiography, one or more focal $\geqslant 5$ mm lesions on MRI scans, clonal bone marrow plasma cells $\geqslant 60 \%$, abnormal serum-free light chain (FLC) ratio $\geqslant 100$ (involved kappa) or $<0.01$ (involved lambda) [5].

The malignant plasma cells produce monoclonal paraprotein, also called M protein, which can bind to any coagulation factor, platelet, von-Willebrand factor, or fibrinogen and can thus cause diverse hemostatic abnormalities [6-7]. Abnormal coagulation tests are commonly seen in plasma cell dyscrasias. However, clinically significant bleeding complications are rarely seen. Several retrospective studies on multiple myeloma did not report bleeding as a presenting symptom [8]. Bleeding rates of $13 \%$, 33\%, and $36 \%$ are seen with IgG, IgA, IgM M proteins, respectively [7] and were reported in a study on 62 patients by Perkins [9]. Due to the limited experience, there is a scarcity of literature available on the management of bleeding complications in plasma cell dyscrasias.

Bleeding tendencies in multiple myeloma can be explained by a variety of mechanisms such as dysfibrinogenemia secondary to the inhibition of fibrin monomers by the FAB portion of paraprotein molecules, paraprotein-induced platelet dysfunction, shortened platelet survival, damage to vascular endothelium, and acquired von-Willebrand syndrome [3]. In our patient, the pathology behind bleeding diathesis is thought to be acquired dysfibrinogenemia with the evidence of prolonged prothrombin time and decreased fibrinogen activity. The patient had the normal activity of von-Willebrand factor, Factor VIII, and IX activity, which ruled out acquired hemophilia in this context.

Treatment therapies that can be used for the symptomatic management of bleeding complications include coagulation factor replacement, fibrinolysis inhibitors, protamine sulfate, Arginine, vasopressin, and platelet factor 4. Plasma exchange and splenectomy can be tried in refractory cases [8]. Though symptomatic treatment can improve the patient's condition temporarily, the mainstay of treatment is always treating the underlying disease. Our patient received symptomatic treatment, including massive transfusion protocol with packed red blood cells, platelets, coagulation factor replacement, vitamin K, and folic acid therapy. Her condition temporarily stabilized with the transfusion of antifibrinolytic (Amicar) targeting acquired dysfibrinogenemia. However, coagulopathy was controlled only when the patient was started on chemotherapy for multiple myeloma.

\section{Conclusions}

Multiple myeloma can rarely present with bleeding complications, which, when untreated, may progress to hemorrhagic shock. It is paramount to have a high index of suspicion for multiple myeloma in a patient with acquired bleeding disorders who is refractory to treatment. Coagulopathy can be controlled only when the patient receives treatment for their underlying disease.

\section{Additional Information \\ Disclosures}

Human subjects: Consent was obtained or waived by all participants in this study. Conflicts of interest: In compliance with the ICMJE uniform disclosure form, all authors declare the following: Payment/services info: All authors have declared that no financial support was received from any organization for the submitted work. Financial relationships: All authors have declared that they have no financial relationships at present or within the previous three years with any organizations that might have an interest in the submitted work. Other relationships: All authors have declared that there are no other relationships or activities that could appear to have influenced the submitted work.

\section{References}

1. Rajkumar SV: Myeloma today: disease definitions and treatment advances . Am J Hematol. 2016, 91:90-100. 10.1002/ajh.24236

2. Kazandjian D: Multiple myeloma epidemiology and survival: a unique malignancy . Semin Oncol. 2016, 43:676-681. 10.1053/j.seminoncol.2016.11.004

3. Medical Masterclass contributors, Firth J: Haematology: multiple myeloma. Clin Med (Lond). 2019, 19:5860. 10.7861/clinmedicine.19-1-58

4. Iwaniec T, Zdziarska J, Jurczyszyn A: Abnormal hemostasis screening tests leading to diagnosis of multiple myeloma. Acta Haematologica Polonica. 2019, 50:32-35. 10.2478/ahp-2019-0006

5. Kumar SK, Callander NS, Hillengass J, et al.: NCCN guidelines insights: multiple myeloma, version 1.2020 . J Natl Compr Canc Netw. 2019, 1:1154-1165. 10.6004/jnccn.2019.0049

6. Saif MW, Allegra CJ, Greenberg B: Bleeding diathesis in multiple myeloma . J Hematother Stem Cell Res. 


\section{Cureus}

2001, 10:657-660. 10.1089/152581601753193869

7. Eby C: Pathogenesis and management of bleeding and thrombosis in plasma cell dyscrasias . Br J Haematol. 2009, 145:151-163. 10.1111/j.1365-2141.2008.07577.x

8. Kyle RA, Gertz MA, Witzig TE, et al.: Review of 1027 patients with newly diagnosed multiple myeloma . Mayo Clin Proc. 2003, 78:21-33. 10.4065/78.1.21

9. Perkins HA, MacKenzie MR, Fudenberg HH: Hemostatic defects in dysproteinemias. Blood. 1970, 35:695707. 10.1182/blood.V35.5.695.695 